\title{
Hybrid Organizations: ORIGINS, StRATEgIES, IMPACTS, AND IMPLICATIONS
}

\author{
Nardia Haigh \\ John Walker \\ Sophie Bacq \\ Jill Kickul
}

This introduction to the special issue on hybrid organizations defines hybrids, places them in their historical context, and introduces the articles that examine the strategies hybrids undertake to scale and grow, the impacts for which they strive, and the reception to them by mainstream firms. It aggregates insights from the articles in this special issue in order to examine what hybrid organizations mean for firms and practicing managers as they continue to grow in number and assume a variety of missions in developing and developed countries. (Keywords: Hybrid Organizations, Social Enterprise, Business and Society)

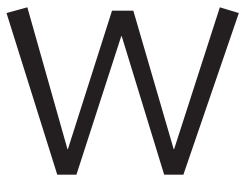

ith the market for socially and environmentally conscious products and services growing to $\$ 290$ billion $^{1}$ and the market for socially responsible investments growing to $\$ 3$ trillion in assets in the U.S. alone (or $12 \%$ of professionally managed funds), ${ }^{2}$ there has naturally been a complementary growth in the popularity of organizations that seek to meet this market opportunity ${ }^{3}$ that we call "hybrid organizations." In our special issue, we define hybrid organizations as those enterprises that design their business models based on the alleviation of a particular social or environmental issue. Hybrids generate income and attract capital in ways that may be consistent with for-profit models, nonprofit models, or both. Authors contributing work to this special issue refer to hybrid organizations (or hybrids) by a variety of terms including "social hybrid venture," "benefit corporation," and "hybrid firm," but central to the use of all terms is the duality of social impact alongside financial sustainability. The term "hybrid organization" reflects the propensity of such enterprises to blend traditionally for-profit practices with traditionally nonprofit practices. Because they can exist as for-profits, nonprofits, 
Nardia Haigh is an Assistant Professor of Management in the College of Management at the University of Massachusetts Boston.

$<$ nardia.haigh@umb.edu>

John Walker is the Director of Finance and Business Development at A-List Education, and an Adjunct Associate Professor at Columbia Business School. <jw2461@columbia.edu>

Sophie Bacq is an Assistant Professor of Entrepreneurship \& Innovation in the D'Amore-McKim School of Business at Northeastern University. <s.bacq@neu.edu> Jill Kickul is the Director of the Social Entrepreneurship Program in the New York University Stern School of Business. <jkickul@stern.nyu.edu> or both, an increasing number of hybrids complement a nonprofit with a for-profit entity. ${ }^{4}$

As one of the first comprehensive collaborations focusing on hybrid organizations, this special issue collates research examining their emergence, their business models and strategies, the ways in which they create and track impact, and their implications for the broader markets in which they operate. We review each of these topics below, and conclude with broad managerial takeaways. By covering these topics, we are able to capture and share insights about what hybrid organizations can mean for traditional firms as they become potential partners, competitors, and acquisition targets.

\section{Origins}

In her book The New Pioneers, Ellis traced the nascent beginnings of entrepreneurship with a social conscious to the 1960s and 1970s and the rise in political consciousness. ${ }^{5}$ This was then complemented by a rise in the number of nonprofit organizations established to address issues relating to environmental degradation, human rights, women's liberation, and to support anti-war efforts. Another phenomenon underpinning the emergence of hybrid organizations includes traditional nonprofits turning to earned revenue in the face of rising costs and growing competition for grants and philanthropic funding. ${ }^{6}$ Further to this, there has been a rise in societal dissatisfaction with the inability of governments and firms to address longstanding issues such as inequality, teen pregnancy, homelessness, substance abuse, and others, alongside technological and economic trends that haven given citizens the ability and confidence to do something about them. ${ }^{7}$

The growing number of hybrid organizations has accompanied legislative innovations such as new business registration categories that protect executives from shareholder action demanding companies maximize profit and prioritize it over a social mission. In the U.S., for example, hybrid organizations can now choose to register as a Benefit Corporation, a Benefit LLC, a Flexible Purpose Corporation, or a Low-Profit Limited Liability Company (L3C). The certification body B Lab is a key protagonist in this movement, as is The American Sustainable Business Council. Since 2008, B Lab has certified 1,212 "B Corporations," operating throughout 121 industries in 38 countries. $^{8}$

The importance of legal and taxation structures cannot be underestimated in fulfilling hybrid organizations' objectives, including both established models of incorporation, partnership, and tax-exempt status together with emerging models of benefit corporations and extended partnership law that integrate the achievement of both the social mission and shareholder value. In their article "Benefit Corporation Legislation and the Emergence of a Social Hybrid Category," Rawhouser, Cummings, and Crane investigate the support for and opposition to 
Benefit Corporation legislation in the U.S. ${ }^{9}$ They found that states characterized by a Democrat majority that passes more bills, a market with firms thriving on sustainability-oriented products, and low nonprofit activity are more likely to enact Benefit Corporation legislation. More significantly, the authors indicate that anyone in favor of, or opposed to, Benefit Corporation legislation can influence the likelihood of a State's enactment of it, because less than ten people or organizations typically contributed to pre-vote testimony.

\section{Strategies}

In common with other social entrepreneurs, hybrid entrepreneurs primarily seek to initiate change to alleviate or compensate for a particular social or environmental problem. In recognizing the power of market-oriented models to effect such change in a sustainable manner, hybrids target interventions that exhibit growth potential and profitability insomuch as they are ultimately self-funding. Previous research has sought to answer questions surrounding what makes or drives a social entrepreneur, ${ }^{10}$ and in this special issue we are concerned with the tactics and strategies such entrepreneurs and their organizations employ to pursue their goals. In particular, this special issue examines the ways in which hybrid organizations create the shared value to which they aspire while remaining economically viable.

The ability to create a mission-driven business that is financially viable is vitally important, since there are examples where hybrids have folded or drifted away from their mission either through acquisition, leadership changes, or fierce competition from traditional businesses that maximize profits. ${ }^{11}$ Santos, Pache, and Birkholz look into these kinds of issues in their article "Making Hybrids Work: Aligning Business Models and Organizational Design for Social Enterprises." ${ }^{12}$ Specifically, they develop a typology of hybrids based on whether social value creation is automatic or contingent on other support or interventions and whether beneficiaries are clients or not. The authors offer advice for the management of each hybrid type so that social entrepreneurs can align financial viability goals with social impact goals and identify the kinds of challenges they may encounter as they adjust their business models for such alignment.

One particular issue faced by social entrepreneurs striving to align financial viability goals and social impact goals is deciding which legal structure will best assist them to do both. In their article "Hybrid Organizations as Shape-Shifters: Altering Legal Structure for Strategic Gain,"13 Haigh, Dowin Kennedy, and Walker investigated 48 hybrid organizations and found that half of them changed their legal structure. Their study examines why social entrepreneurs initially choose for-profit over nonprofit or vice versa, explains why half of them changed their initial structure, and shows the implications that such changes can have for companies partnering with hybrids.

Hybrid organizations' business models are often built to serve markets that are traditionally underserved by mainstream firms and by governments, both of which tend to cater to majorities. One such market is the labor market composed of people with disabilities. Disabled people face significantly higher hurdles to 
gaining and sustaining employment than able-bodied people do because they are perceived to have fewer skills. In his article "How Hybrid Organizations Turn Antagonistic Assets Into Complementarities,"14 Hockerts defines antagonistic assets as assets "that a priori make the commercialization or marketing of a product or service more difficult," typically leading firms to avoid them where possible. The type of avoidance of so-called "antagonistic assets" Hockerts investigates is the bias of traditional labor markets towards able-bodied people. Rather than avoid them, hybrid organizations often embrace antagonistic assets by identifying and developing "hidden complementarities" between organizational goals and skill sets, and by creating demand for them.

\section{Impacts and Implications}

A further aim of this special issue is to offer content focused on the impacts and implications of hybrid organizations. Social enterprises have been celebrated for their aim to create positive social impacts, ${ }^{15}$ and it has been argued that the best social enterprises will deliver a better social return on investment than the best for-profit, public, or charitable organizations. ${ }^{16}$ Others have argued that social enterprises may also create unintended negative impacts, ${ }^{17}$ and they speak to the challenges hybrids have faced when measuring their outcomes ${ }^{18}$ and determining whether measured outcomes represent failure or success. ${ }^{19}$ The article from Holt and Littlewood called "Identifying, Mapping and Monitoring the Impact of Hybrid Firms" ${ }^{20}$ examines both positive and negative impacts of hybrid organizations based on their study of 20 hybrids in Sub-Saharan Africa, develops a process that managers can use to identify and track impact indicators, and illustrates how to use it in practice.

Following Holt and Littlewood is an article by Lee and $\mathrm{Jay}^{21}$ investigating the implications of hybrids for mainstream companies operating in the same industry. Although they often operate in under-served niche markets, some hybrids compete in mainstream markets, which makes them of interest to traditional firms as targets for collaboration, competition, and/or acquisition. ${ }^{22}$ To date, only anecdotal evidence has been presented about how hybrids influence mainstream firms, and some researchers have questioned the degree to which operating a for-profit business with embedded consciousness could ever be widely applied or achieve the sustained societal and environmental transformation for which they strive. ${ }^{23}$ Lee and Jay's article "Strategic Responses to Hybrid Social Ventures" 24 addresses the issue of how established mainstream companies respond to the entry of hybrid organizations into their markets. The authors investigate the ways in which eight mainstream companies have responded to the entry of a hybrid into their markets, and they develop a framework that can guide others in the same situation.

\section{Managerial Take-Aways from the Special Issue on Hybrid Organizations}

The articles in the special issue offer a wealth of insights and advice for those building and managing hybrid organizations, for those managing traditional firms that collaborate or compete with hybrid organizations, for those managers 
seeking deeper engagement with social or environmental issues, and for those doing research on hybrid organizations.

\section{You Can Influence the Hybrid Organization Trend}

The current growth in hybrid organization numbers is reinforced by the passage of supportive legislation, which gives advocates (and opponents) of hybrids an avenue to influence both the likelihood and shape of such legislation. In finding that only small numbers of people and organizations typically submitted testimony when Benefit Corporation legislation was discussed and debated, Rawhouser, Cummings, and Crane's work shows that anyone wanting to influence such legislation in their region often can. ${ }^{25}$ A second avenue of influence identified by the same study exists in the certifications that often precede the implementation of Benefit Corporation legislation, in that companies favoring significant social and environmental agendas can add their weight to the trend by having their commitments certified by organizations such as B Lab. ${ }^{26}$

\section{Design Flexible Hybrid Organizations that Align Mission with Profit}

The ability of hybrid entrepreneurs to develop innovative business models and strategies that balance the risk of mission drift with the risk of financial insolvency is vital, and Santos, Pache, and Birkholz recommend that business models characterized by a strong alignment between profit and social impact and a relatively simple value chain increase the likelihood of being sustainable. ${ }^{27}$ Various types of business model innovations, these authors found, further influence the types of challenges hybrid organizations will face and the strategies they need to employ to attract funding. Perhaps more fundamentally, the choice that hybrids make about legal form will have strategic implications for them. Haigh, Dowin Kennedy, and Walker found that the legal form serves as a vehicle to balance social and financial needs, rather than being an ideal target in itself. ${ }^{28}$ Therefore, used as a strategic tool, hybrids' flexibility with regard to their legal form will grant them access to certain types of funding or partnerships. Their findings are particularly interesting and can inform the needs of hybrid organizations with regard to funding and earning revenue, which can shape future developments in the social finance and impact investing spheres.

\section{Traditional Firms Can Leverage Hybrid Structures and Strategies}

A theme among the articles in this special issue is that firms can use hybrid structures and strategies to further their commitment to social and environmental goals by collaborating with hybrids or by adopting relevant elements of hybrid structures and strategies. ${ }^{29}$ Haigh, Dowin Kennedy, and Walker showed that hybrids may be willing to alter their legal structure to enter the right strategic partnership, and Hockerts ${ }^{30}$ recommended that firms consider developing partnerships with hybrids to identify currently hidden asset complementarities. Santos, Pache, and Birkholz ${ }^{31}$ offered practicing managers four levers to adapt their strategic positioning in a competitive landscape that is increasingly focused on social issues: governance, organizational structure, human resource processes, and performance management systems. 
In concurrence with Santos, Pache, and Birkholz, ${ }^{32}$ Hockerts $^{33}$ finds that innovations by hybrids are diffusing into and proving successful in mass markets, which leads to the recommendation that firms cultivate a culture of open innovation. Indeed, hybrids' search for market disequilibria leads them to complement rather than enter into fierce competition with companies they perceive to be driven by similar societal goals. To that point, Lee and Jay ${ }^{34}$ also show how hybrids can serve as allies to established companies in the conduct of their sustainability strategies. The benefits of such a "non-zero sum competition" mindset include that hybrids serve as incubators for new practices that can then gain scale and impact when infused into the collaborating firm. Key to the realization of these alliances (or even acquisitions) is the identification of some sustainable orientation within customers, employees, and other stakeholders, and the willingness of a hybrid to enter into an arrangement that would advance the collaborating firm's sustainability strategy. Indeed, as Lee and $\mathrm{Jay}^{35}$ indicate, potential challenges may arise for a hybrid relating to the authenticity of its values, organizational identity, and culture. Hybrids must balance these challenges with the potential for upscaling impact and positive network effects often achieved by collaborating with larger corporations.

\section{Learn to Identify Both Positive and Negative Impacts of Conducting Business}

A final important take-away from this special issue is that a key component of successful social value creation is understanding the positive and negative impacts, which stakeholders they are affecting, and the possible trade-offs they imply. ${ }^{36}$ Holt and Littlewood ${ }^{37}$ highlight the importance of acknowledging context embeddedness of hybrid solutions. The Hy-Map process they propose can help to address the variability that hybrids face in terms of context, social mission, and hybridity of their business model. For managers of traditional firms, the Hy-Map model serves as a useful template that can facilitate the identification and tracking of positive and negative impacts felt by a wide range of stakeholders that might normally be treated as externalities and thus overlooked by traditional stakeholder or risk analyses.

\section{Concluding Thoughts}

Our common goal in this special issue has been to contribute to the increasing levels of research and activity around the utilization of hybrid organizations to create sustainable social value at scale. The evolution of such organizations is an early stage, and many stages will occur in the future that shape and form the resulting marketplace. This special issue provides a resource of objective recommendations for managers, practitioners, and entrepreneurs to use as they create, grow, and sustain their organizations. While much work remains, we look forward to further achievements and to the next series of research and publications focusing on this very important and transformational sector.

\section{Notes}

1. Lifestyles of Health and Sustainability (LOHAS), <www.lohas.com/about>, accessed January 3, 2015. 
2. USSIF, "Report: Socially Responsible Investing Assets in US Top \$3 Trillion; Nearly 1 Out of Every 8 Dollars Under Professional Management," 2010, <http://ussif.org/news/releases/ pressrelease.cfm?id=168>, accessed August 12, 2011.

3. G.M. Kistruck and P.W. Beamish, "The Interplay of Form, Structure, and Embeddedness in Social Intrapreneurship," Entrepreneurship Theory and Practice, 34/4 (July 2010): 735-761.

4. J. Battilana and M. Lee, "Advancing Research on Hybrid Organizing - Insights from the Study of Social Enterprises," The Academy of Management Annals, 8/1 (2014): 397-441; J. Battilana, M.Lee, J. Walker, and C. Dorsey, "Search of the Hybrid Ideal," in Stanford Social Innovation Review, 10/3 (Summer 2012): 51-55.

5. T. Ellis, The New Pioneers: Sustainable Business Success through Social Innovation and Social Entrepreneurship (Chichester: John Wiley \& Sons, 2010).

6. J.G. Dees, "Enterprising Nonprofits," Harvard Business Review, 76/1 (January/February 1998): 54-67.

7. J. Kickul and T.S. Lyons, Understanding Social Entrepreneurship: The Relentless Pursuit of Mission in an Ever Changing World (New York, NY: Routledge, 2012); M.T. Dacin, P.A. Dacin, and P. Tracey, "Social Entrepreneurship: A Critique and Future Directions," Organization Science, 22/5 (2011): 1203-1213.

8. B Lab, <http://bcorporation.net/>, accessed February 4, 2015.

9. H. Rawhouser, M. Cummings, and A. Crane, "Benefit Corporation Legislation and the Emergence of a Social Hybrid Category," California Management Review, 57/3 (Spring 2015).

10. S. Bacq, C. Hartog, and B. Hoogendoorn, "Beyond the Moral Portrayal of Social Entrepreneurs: An Empirical Approach to Who They Are and What Drives Them," Journal of Business Ethics, online November 19, 2014.

11. J. O'Toole and D. Vogel, "Two and a Half Cheers for Conscious Capitalism," California Management Review, 53/3 (Spring 2011): 60-76.

12. F. Santos, A.-C. Pache, and C. Birkholz, "Making Hybrids Work: Aligning Business Models and Organizational Design for Social Enterprises," California Management Review, 57/3 (Spring 2015).

13. N. Haigh, E. Dowin Kennedy, and J. Walker, "Hybrid Organizations as Shape-Shifters: Altering Legal Structure for Strategic Gain," California Management Review, 57/3 (Spring 2015).

14. K. Hockerts, "How Hybrid Organizations Turn Antagonistic Assets into Complementarities," California Management Review, 57/3 (Spring 2015).

15. A.J. Hoffman, K.K. Badiane, and N. Haigh, "Hybrid Organizations as Agents of Positive Social Change: Bridging the For-Profit \& Non-Profit Divide," in K. Golden-Biddle and J. Dutton, eds., Using a Positive Lens to Explore Social Change and Organizations: Building a Theoretical and Research Foundation (New York, NY: Routledge, Taylor and Francis Group, 2012), pp. 131153; F.M. Santos, "A Positive Theory of Social Entrepreneurship," Journal of Business Ethics, $111 / 3$ (December 2012): 325-351.

16. British Council, "What Will Social Enterprise Look Like in Europe by 2020?" 2014, <www. britishcouncil.org/europe/our-work-in-europe/social-enterprise>, accessed September 20, 2014.

17. Z.D. Kaufman, "Social Entrepreneurship in the Age of Atrocities: Introduction," in Z.D. Kaufman, ed., Social Entrepreneurship in the Age of Atrocities: Changing Our World (Cheltenham, UK: Edward Elgar, 2012), pp. 1-19; J. Clifford, K. Markey, and N. Malpani, Measuring Social Impact in Social Enterprise: The State of Thought and Practice in the UK (London: E3M, 2013).

18. Kickul and Lyons, op. cit.; J. Ormiston and R. Seymour, "Understanding Value Creation in Social Entrepreneurship: The Importance of Aligning Mission, Strategy and Impact Measurement," Journal of Social Entrepreneurship, 2/2 (2011): 125-150.

19. J. Jay, "Navigating Paradox as a Mechanism of Change and Innovation in Hybrid Organizations," Academy of Management Journal, 56/1 (February 2013): 137-159.

20. D. Holt and D. Littlewood, "Identifying, Mapping, and Monitoring the Impact of Hybrid Firms," California Management Review, 57/3 (2015).

21. M. Lee and J. Jay, "Strategic Responses to Hybrid Social Ventures," California Management Review, 57/3 (Spring 2015).

22. N. Haigh and A.J. Hoffman, "Hybrid Organizations: The Next Chapter of Sustainable Business," Organizational Dynamics, 41/2 (2012): 126-134.

23. O'Toole and Vogel, op. cit.

24. Lee and Jay, op. cit.

25. Rawhouser, Cummings, and Crane, op. cit.

26. B Lab, op. cit.

27. Santos, Pache, and Birkholz, op. cit. 
28. Haigh, Dowin Kennedy, and Walker, op. cit.

29. Ibid.

30. Hockerts, op. cit.

31. Santos, Pache, and Birkholz, op. cit.

32. Ibid.

33. Hockerts, op. cit.

34. Lee and Jay, op. cit.

35. Ibid.

36. Hockerts, op. cit.

37. Holt and Littlewood, op. cit. 